\title{
The Pushing Approach of The Education Modernization in China
}

\author{
Defen Qi ${ }^{1, a}$, Zhongliang Guan ${ }^{2, b}$ Deliang Qin ${ }^{3, c}$ Kexin Liu
}

${ }^{1}$ The Postdoctoral Research Station of China Industry Safety Research Center, China

${ }^{2}$ Beijing Jiaotong University, China

${ }^{3}$ Harbin Education bureau, China

${ }^{4}$ Harbin Institute of Technology, China

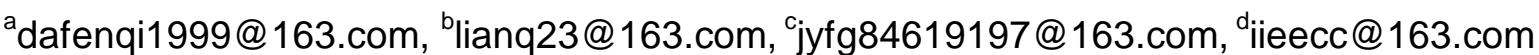

Keywords: Education, modernization, pushing approach.

Abstract. In the paper, we are going to analyze the facing difficulties and challenges in the process of promoting the modernization in our country based on the basic requirement of educational modernization to put forward the pushing approach of educational modernization in our country, which is promoting the modernization of educational concept, educational content, educational conditions and teaching staff, pushing educational informatization, internationalization and the rule of law, offering theoretical support to achieve educational modernization basically in our country.

\section{Introduction}

Educational modernization is the important basis of modernization of the country. Speeding up the modernization of education is the request to carry out the spirits of the party's eighteen big eighteen conference, the realistic demand of managing satisfying education, is basic requirements to the development of economical society, and is also the surest way to enhance the level of quality education itself. Educational modernization means reaching the world advanced level gradually in terms of educational idea, educational content, educational conditions, teaching staff and educational management, developing new workers and high-quality talent people to adapt to participate in the international economic competition and the comprehensive national strength competition. The basic task is to meet the needs of social development and provide powerful talents support for the modernization construction.

\section{The basic meaning to achieve educational modernization}

To achieve a higher level of education. Education is a national public service product. The popularization of educational level is about the overall level of the national economic and social development is the basic scale to measure the country's modernization. The popularization is the key to improve the comprehensive competitiveness of national soft power and universalization. American education sociologist professor Martin proposed, namely along with the economic and social progress, the development of higher education from the elite to popularize the popularization. Higher education gross enrollment ratio below $15 \%$ for the elite higher education, between a $15 \%$ and $50 \%$ for mass higher education, more than $50 \%$ to affordable higher education. In the phase of elite education, higher education is short of resource and social privileges. In the stage of mass education, the popularization of higher education is the inevitable requirement of modern industrial society. Popularizing higher education is the only way to the informational society[1]. Universal education is to implement pre-school education, compulsory education universalization equalization, and diversification of high school education, vocational education scale, the popularization of higher education, lifelong education and whole-staff-participation.

To form a fair education benefiting all people. Educational fair is the important foundation of social justice, which not only concerns the country's economic prosperity and social progress, but also affects the public welfare. Educational fair is to make every child enjoy the chance to receive education 
and try to get 1.3 billion people enjoy better and fair education to develop their own, contribute to society, and benefit the ability of the people. Educational fair is to raise the level of school equipment gradually to realize the equally basic public education services and narrow the gap between regions by improving the educational conditions. Adhere to the welfare and general education is the way to guarantee poor students and migrant workers' children to receive a good education in accordance with the law.

To provide more abundant education. High-quality education is the eternal pursuit of education development. High-quality education is to make students form an active characteristic and a healthy personality by optimizing education resources allocation. The high-quality education resources should be expanded gradually to meet the needs of the masses "studious". The reform of the personnel training mode, the innovation of the personnel training mechanism, as well as the students' ideological and moral qualities, scientific and cultural quality and health quality is on the important position, will only make students learn knowledge skills, learn to survive living and the life. The combination of the education of information technology in teaching will make the high-quality education resources expand further and further.

To improve the system of dynamic education. A dynamic education system is a basic guarantee of educational modernization. Deep reform of education in key areas and crucial links, management system, education system, teaching contents, education methods, examination evaluation system reform of promoting, and the establishment of modern school system, the formation and development rule of market economy and education to basic education system fit, full of vitality, form combining education with economy, society, science and technology, the development of effective interaction mechanism.

\section{The plight of achieving educational modern}

Educational development is not balanced. Influenced by binary pattern of education under urban-rural dualism formed for a long time, there are still quite differences in educational scale, the school running conditions, the teacher's troop quality and educational quality between urban and rural areas in China. education in facilities, teachers, teaching and management exist in many aspects, such as uneven phenomenon, relatively older rural teachers, shortage of science teachers equipped with insufficient, rural teachers overall quality lags behind that of the urban area, is still a big gap between urban and rural education level. School students disequilibrium, urban schools are overcrowded, and the rural school students is insufficient, the crowds; School funds imbalance, the rural education funds nervous, often need to students participating in work-study programs complement insufficient funds. Education investment in our country the status of the uneven distribution between different areas has a long history, from the aspects of education investment data, between regions and the same area between different provinces, and even within the same province, between urban and rural education the allocation of funds for the amount of money and embrace education, etc., is a big difference[2].. Due to historical, geographical factors, macroscopic education investment policy and so on many factors, in, in the western region education seriously lagging behind the eastern coastal areas, the rural education seriously lagging behind the city( fig.1). 

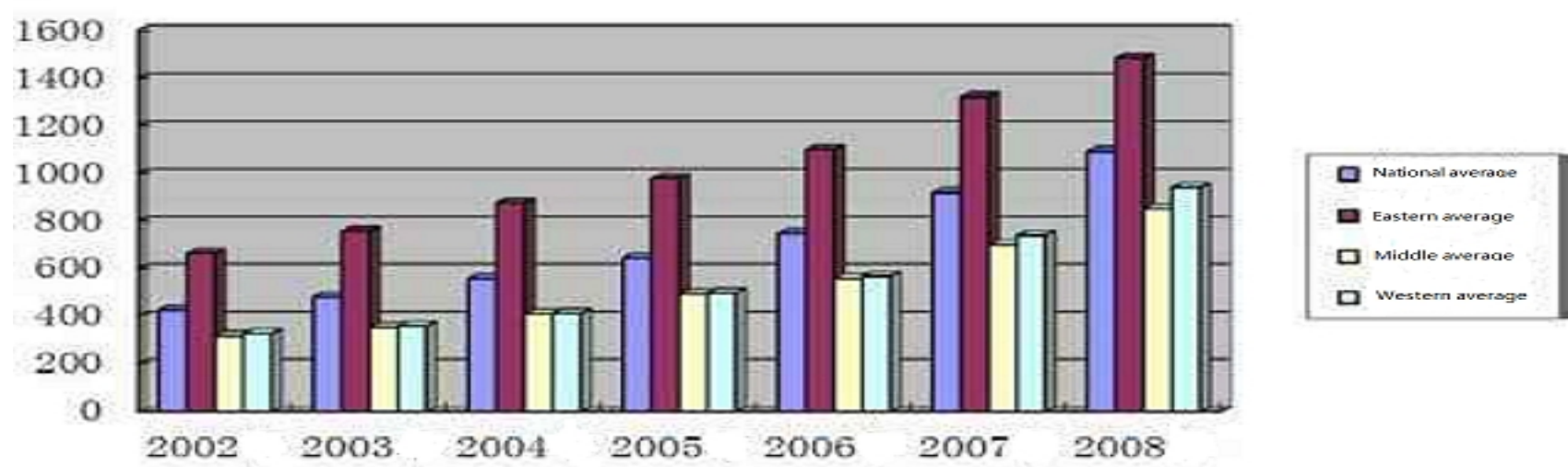

Fig. 1 Level of educational investment in different regions

At the same time, the backward education and the pace of economic and social development, limit the area can lead to the development of education lag behind and the lagging economic development into a vicious cycle, on the whole, to form the "east high and west low, central China" situation, resulting in between regions, urban and rural education gap is widening. The same between cities, between the main educational conditions, education level there is a big gap between the county.

Educational structure is not perfect. At present, our country's education in the education level, education category structure, there exist some problems, professional set up two general education structure spindle structure, weakening of coordinated with our industrial structure, Labor structure is not enough. And America, Japan and other countries in comparison, Chinese education structure and industry structure is not matching. Tertiary education in our country presents "top-heavy" inverted pyramid structure. The attenuation of the compulsory education is bound to shake the foundations of the higher education, the irrational development of higher education, will cause the outflow of knowledge unemployment and intelligence, resulting in a lot of waste of resources and the welfare loss[3].. Preschool education is relatively weak, inadequate public kindergarten, universality kindergarten share is low, fully equipped with public kindergarten teachers in place, preschool education popularization level is not high. A slow development of secondary vocational education and secondary vocational school education condition is relatively weak, not prominent, the professional characteristics of rural vocational education school strength is not strong, weak secondary vocational graduates market adaptability, vocational education attraction and service ability still need to strengthen the economic and social development[4].. Higher education development direction and service functions need to be further perfect, after education, community education, and aging education still need to further strengthen. The private education and public education develop unbalanced. In recent years, China's basic situation of the development of various schools: public education is "gas" (size) not "force" (efficiency); Private education squeezed; the education swarmed into China, Chinese students flock.

\begin{tabular}{|l|l|l|l|l|}
\hline Country & $\begin{array}{l}\text { The Stages of } \\
\text { Economic growth }\end{array}$ & $\begin{array}{l}\text { Industrial } \\
\text { Structure }\end{array}$ & $\begin{array}{l}\text { Employment } \\
\text { Structure }\end{array}$ & EducationalStructure \\
\hline China & Middle industrialization & II $>$ III.I & I $>$ III $>$ II & II $>$ I $>$ III \\
\hline India & Middle industrialization & III $>$ $>$ II & I $>$ III $>$ II & II $>$ III \\
\hline Korea & Late industrialization & III $>$ II $>$ I & III $>$ II $>$ I & II $>$ III.i \\
\hline Japan & Late industrialization & III $>$ II. $>$ I & III $>$ II $>$ I & II $>$ III $>$ I \\
\hline Ameria & Post industrial period & III $>$ II $>$ I & III $>$ II $>$ I & III $>$ II $>$ I \\
\hline
\end{tabular}

Table. 1 Economic development phase and educational structure in various countries

Educational layout is unreasonable. School layout is a country or a region on the geographical spatial distribution structure, it has to do with social and economic development level and population distribution are closely related. The school layout is scientific, is directly related to the use of education resources efficiency and the development of education[5].. By adjusting urban overall planning, factors such as population changes, China's education layout are unreasonable. With the advancement of urbanization process, in May 2001 the state council on the decision of the elementary education reform 
and development "in the clear after put forward to adjust the layout of rural primary and secondary schools, to adjust the layout of rural primary and secondary schools, primary schools in China the number from 2001 in 491,300 to 2001 by 201,400, a drop more than $50 \%$, over the same period the number of students in school from 125.4347 million to 94.5106 million, a drop of more than $30 \%$. For the sharp drop in the number of rural primary and secondary school students to get far, not only caused the family education cost and the student dropout rates rise, and also caused the student to go to school and increase in the number of unsafe factors in residence. Existing school resources are imbalanced. Many school buildings in cities are even in short supply, local deficiencies and idle phenomenon.

To improve school running conditions. At present, schools in cities basically have a library, computer lab, language lab, and stadium. However, the rural parts of the schools language lab, the gym, or even necessary laboratory have not yet been fully equipped. According to China national land area is not up to standard, China and many of the national school building area is not up to standard, part of the rural schools lack of necessary conditions for offering education and basic education teaching facilities. Broadband Internet access school proportion is not high, but the class is apart from the national, provincial requirements are broadband Internet access is a gap, many rural schools, ordinary class multimedia teaching equipment penetration is far less than $77 \%$ of the provisions of the state.

Educational connotation development needs to be improved. Some teachers' educational concept is still relatively backward. Full implementation of quality education has not been fundamental implement, the phenomenon of one-sided pursuit of graduation rates is still severe and students' schoolwork burden is still heavy. The students' psychological quality, physical and mental health, and moral character education still need to further strengthen. Education teaching reform is also facing many difficulties, the education teaching evaluation system also needs to be further improved.

Educational investment is relatively short. Educational investment is a basic and strategic support of their country's long-term development investment, is the basic guarantee of modernization of education and the important support. Although in recent years our country education general budget increases year by year (see chart 5), from 325.502 billion Yuan in 2002 to 2014 in 2.257051 trillion Yuan, but the education of public fiscal expenditure proportion was not a significant rise (figure 6), is a part of the downward trend. Under the dual system, accounts for the vast majority of rural population have only half of the nation's compulsory education funds and less than half of the infrastructure investment. Education in relatively insufficient, severely restricts the education modernization level.

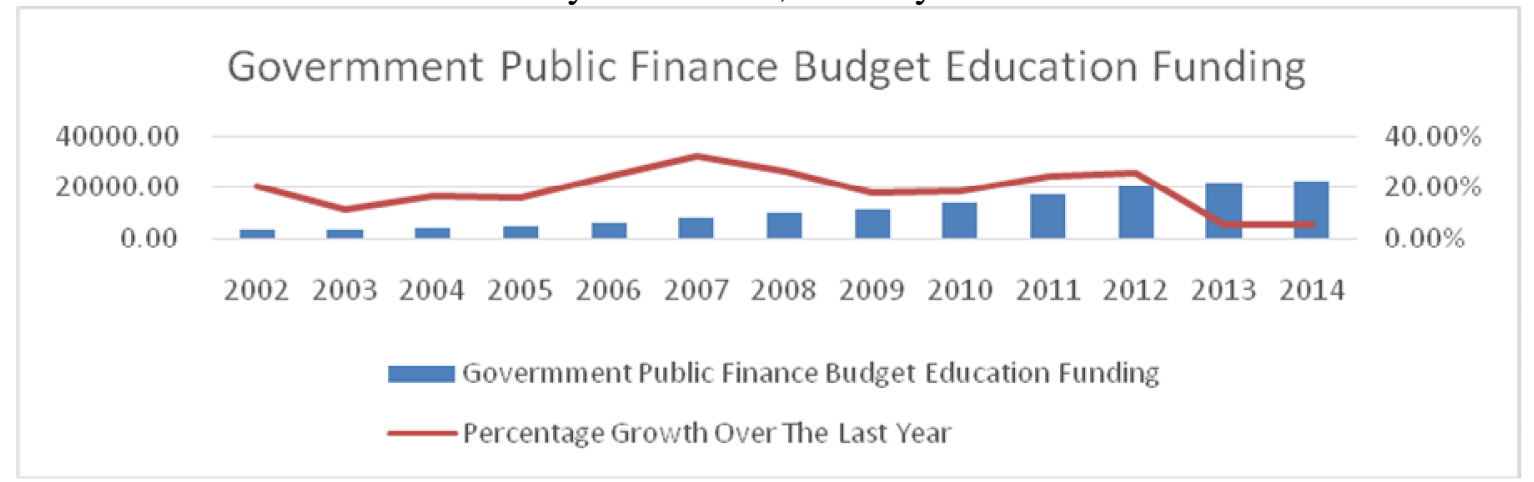

Fig 2. The Public finance education budget and the Proportion of in GDP 


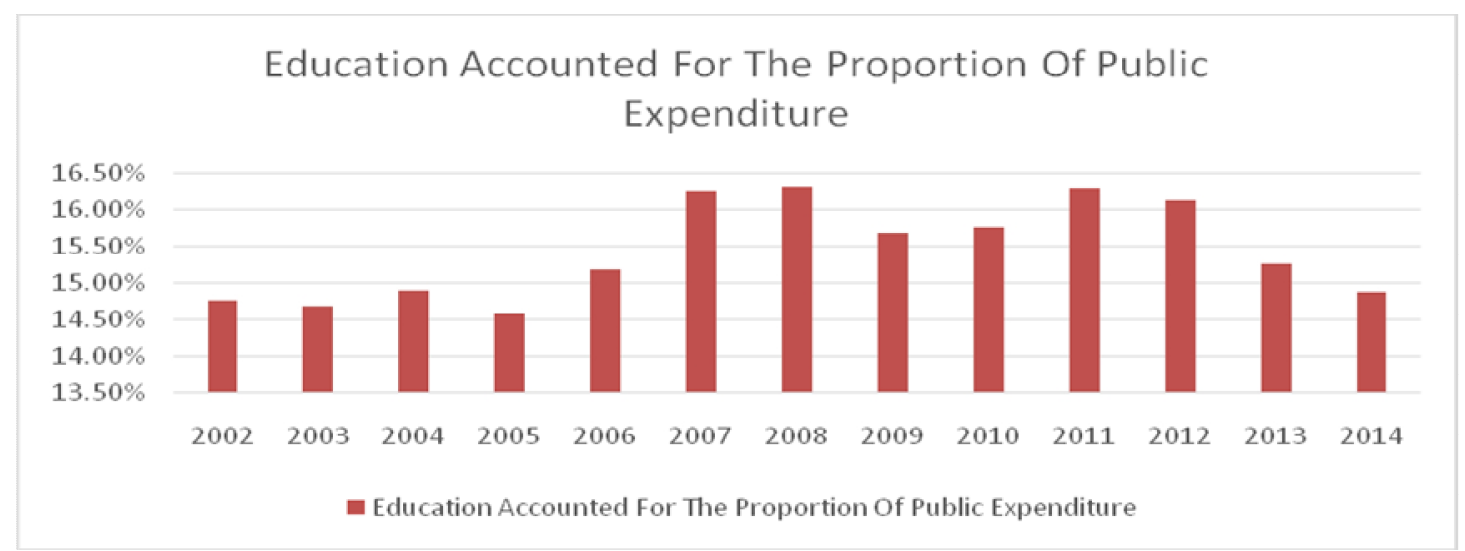

Fig 3. Education accounts for the proportion of public finance expenditure on Education

\section{The basic route of promoting the modernization of education}

To strengthen the thought construction and realize the modernization of education concept. The core of education modernization is human modernization, and its symbol is the educator education ideology of modernization and the modernization of the ideas of the students. Must adhere to the world and the future, face modernization, setting up for the human peace and progress of people, train people for the great rejuvenation of the Chinese nation, to the lifelong development of each and every one lays a foundation of responsibility consciousness and sense of mission, always remember to do a good job in the people's satisfactory education career objective, fully implement the education policy, the full implementation of quality education, to promote each education workers thought state and inner structure, efforts to promote each student's modern talent quality.

To deepen the basic education curriculum reform and realize the modernization of education content. Cultivation of the comprehensive development of socialist builders and successors, and is the basic task of promoting the modernization of education. Education is the basic requirement of education work, promote the students' growth is the starting point and the foothold of all school work, people-oriented, promote reform and development of quality education is the education of the strategic topics. Adhere to make people moral, deepen the socialism with Chinese characteristics and the Chinese dream education, carry out the system of socialist core values education, and strengthen the Chinese excellent traditional culture education. Giving full play to the advantages of education resources, expand the foundation education course reform efforts, up and down through, organic link, coordinate with each other, scientific and reasonable curriculum system. The implementation of the national curriculum plan, improve the educational function of teaching subject, abundant school-based courses, strive to improve the level of curriculum implementation. Construction of excellent courses and the realization of quality education network teaching resources sharing. Actively explore independently based on curriculum standards, high efficiency, lively classroom teaching mode, persistence and, establishing evaluation system to promote students' development as the goal, let each student all-round development, individuation development.

To strengthen the construction of infrastructure and realize modernization education condition. The modernization of operating conditions is the premise and basis of educational modernization. Educational modernization doesn't get its material basis without modernization educational condition. According to the needs of urban development in our country, advance and scientific planning and layout of primary and secondary schools, synchronize the education planning and urban development will adapt to the future development needs. Optimize the existing school buildings resources reorganization, make full use of the old town shantytown renovation project to increase land for building. Synchronization of the scientific planning, completes the school district construction, maximum limit satisfy the demand in the new district. Strengthen the education, management in planning land in strict accordance with the small and medium-sized school location requirements for planning and site selection, construction and residential construction to ensure that 
the school start simultaneously, synchronous put into use. To improve the conditions of primary and secondary schools and make primary and secondary school construction standards, to determine the construction scale of primary and secondary schools, the quality and standards. Improve the level of school equipment, strengthen the smaller subjects such as sound, body, beauty instruments and equipment to guarantee the quality education into implementation. To strengthen the construction of basic education, fully meet the requirements of running schools, school construction to build up the primary and middle schools "behind the school" in one hundred.

To develop the education of all types and at all levels implement modern education system. Relatively complete modern education system is the important carrier of promoting the modernization of education[6]. To adhere to the focus on the promotion of fair and improve the quality of connotative development way, speed up the construction in accordance with the situation of modern education system, to better meet the demand of the masses of all nationalities multi-level and diversified education. Vigorously develop preschool education, optimize the structure of preschool education development, expand public preschool education resources, reasonable layout of the public kindergarten, and improve the proportion of Pratt \& Whitney kindergarten. To promote the balanced development of compulsory education high, to strengthen the construction of weak urban schools, high schools do a good job in the township center and school (including school), do a good job in every primary and middle schools, promote the balanced, the high development of compulsory education. Strengthen the special group education, students focus on left-behind children, single parent families of poor students groups such as students, family education, make students healthy development. Strengthen the migrant children education to ensure that they can obtain equal right to education. To strengthen the construction of the connotation of average high school, promote the development of diversification, characteristic of average high school. Scientific planning vocational education, form the service demand, open integration, longitudinal flow, two-way communication, modern higher vocational education system in the framework and the overall layout. Adjusting and optimizing vocational colleges professional Settings, major setting and industrial demand, the course content and the professional standards, teaching process and production process of three docking. We should speed up the development of higher education; vigorously promote intensive and characteristics of running a school, college transformation development and characteristic development guide colleges and universities; strengthen community education and old age education, and promote the learning city construction.

To strengthen teacher team construction and realize the modernization of their teachers. The team's modernization is the premise and guarantee of the modernization of education. We should take strengthening teachers team construction as the basis of promoting the modernization of education, to create a noble ethics, business skill, reasonable structure, dynamic professional teacher's team with high quality. To pay great attention to the teacher's ethics construction, under the background of profound changes in the current economic society, people's thought concept, value orientation, dramatic changes happening in ethics, it also puts forward unprecedented challenges on teachers' professional ethics, the professional ideal and professional ethics education in teachers team construction, establish a sound education, propaganda, measure, monitor, and reward the ethics construction of long-term mechanism of combining the ethics performance review as teachers, engage (recruit) the primary content and evaluation, and improve overall teachers ideological and moral quality. Strengthen the team construction, in-depth implementation of technocrat principal pilot training project, thousands of backbone of headmaster training project, the principal reserve talented person echelon projects, rural power train project, improve team management level of the principal. Strengthen teachers team construction, practice of general secretary of the "four haves" good teacher standard, we launched the "good of the party and the people satisfied with the teacher" theme education practice, strengthening teachers' training, strengthening the construction of excellent backbone teachers echelon, cultivate noble ethics, business skill, vibrant high-quality professional teachers. To strengthen the research staff team construction, comprehensive building culture of "hard thinking consciousness and research ability, guide the high level and good comprehensive quality" 
excellent research team member. Strengthening the cadres team construction, and strive to enhance the professional quality of the cadres and to promote education reform and development of practice ability, improve the ability to promote the modernization of education guidance.

\section{Conclusions}

Conclusion, In the process of promoting the modernization of education in China, The realization of the human modernization is the core essence Despite facing many difficulties and challenges, Multiple pathways can contribute to the achievement of this goal, the First, implement quality education, to promote each student's modern talent quality. The second, To deepen the basic education curriculum reform and realize the modernization of education content.The third,To set up implement modern education system, To satisfied the needs of all people. This requires us to integrate all kinds of elements, take a variety of ways. Education modernization is a long, continuous process. According to the changes of the situation and people's needs, we must constantly adjust the strategy and development mode.

\section{References}

[1] $\mathrm{Xu}$ Minjuan. Analysis of key educational indicators in OECD countries, Contemporary Educational Science,3,( 2011 )

[2] Chai Xuqing Zhang Xingqian. Regional Structure of Educational Investment in China, Theoretical Study, Vol.8. 83-87(2013)

[3] Ding Ding, Educational Structure, Industrial Structure and Employment Structure, Economic Forum, 11,(2006)

[4] He Chunmei, The Current Problems and Suggestions of China's Educational Structure, Education Review,9, (2006)

[5] Shiren Bing, Research and Inspiration from Foreign Countries about the School Layout Adjustment, Comparative Education Research, 12,(2004)

[6] Michael D . Swaine and Ashley J . Tellis . Interpreting China's Grand Strategy : Past,Present,and Future. Santa Monica,CA,RAND Publishers,2000. 